\title{
Managing Manufacturing Complexity Drivers on Performance - An Initial Study
}

\author{
Leang Suh Huah ${ }^{1}$, Wan Hasrulnizzam Wan Mahmood ${ }^{1,2}$,, Muhamad Arfauz A Rahman ${ }^{l}$ \\ ${ }^{1}$ Sustainable and Responsive Manufacturing Research Group, Faculty of Manufacturing Engineering, Universiti \\ Teknikal Malaysia Melaka, 76100 Hang Tuah Jaya, Melaka, Malaysia \\ ${ }^{2}$ Faculty of Engineering Technology, Universiti Teknikal Malaysia Melaka, 76100 Hang Tuah Jaya, Melaka, \\ Malaysia
}

\begin{abstract}
Manufacturing systems, in pursuit of cost, time and flexibility optimisation are becoming more and more complex, exhibiting a dynamic and nonlinear behaviour. Unpredictability is a distinct characteristic of such behaviour and effects production planning significantly. Complexity continues to be a challenge in manufacturing systems, resulting in ever-inflating costs, operational issues and increased lead times to product realisation. This challenge must be met with appropriate decision-making by manufacturing companies to secure competitive advantage without compromising sustainability. Assessing complexity realises the reduction and management of complexity sources which contribute to lowering associated engineering costs and time, improves productivity and increases profitability. Therefore, this study was undertaken to investigate the priority level and current achievement of manufacturing performance in Malaysia's manufacturing industry and the complexity drivers on manufacturing productivity performance. The results showed that Malaysia's manufacturing industry prioritised product quality and they managed achieved a good on-time delivery performance. However, for other manufacturing performance, there was a difference where the current achievement of manufacturing performances in Malaysia's manufacturing industry is slightly lower than the priority given to them. The strong correlation of significant value for priority status was observed between efficient production levelling (finished goods) and finish product management while the strong correlation of significant value for current achievement was minimised the number of workstation and factory transportation system. This indicates that complexity drivers have an impact towards manufacturing performance. Consequently, it is necessary to identify complexity drivers to achieve well manufacturing performance.
\end{abstract}

\section{Keywords: Manufacturing complexity driver, Current Manufacturing Performance, Priority, Current Achievement,}

\section{INTRODUCTION}

In the course of this progress, global manufacturing networks became more and more complex inter alia due to the geographical distribution of sites, a growing product diversity, sophisticated manufacturing processes and many other aspects [1]. Many industries are looking the best ways to improve productivity. However, there are many factors that influence the productivity reduction. One of the factors is complexity [2]. Manufacturing is a cornerstone of the world economy. The manufacturing share of global GDP is $16 \%$, it created 62 million jobs in 2000 and 45 million in $2010,30-50 \%$ of service jobs are in manufacturing, the advanced economies' trade deficit in labour- intensive goods is $\$ 342$ Billion and \$726 Billion is their trade surplus in innovative goods [3]. In Eleventh Malaysia Plan, 2016-2020, sustainability is fundamental to the planning growth, especially in the manufacturing sector. The manufacturing sector is one of the fields contributing to Gross Domestic Profit (GDP) Malaysia for the second quarter of 2016. Malaysia has a goal to grow as an advanced economy by 2020 with robust, low-carbon, resource efficient and socially inclusive manner [4].

Most of the companies today struggle with fierce demands on efficiency, flexibility and sustainability connected customisation and the introduction of new sustainable products which increases production 
complexity [5]. Manufacturing systems are becoming complex to fulfil the requirements of the increasing product quality and flexibility demands [6]. Complexity is still one of the biggest challenges in manufacturing due to increased variety, market volatility and distributed global manufacturing [7-8]. Especially the identification of the most relevant network segments from a complexity perspective is a critical success factor for a company's competitiveness since it provides information to management about what kind of improvement measures might be most urgent and might deliver the most favourable impact in a certain economic situation [9].

In general, the manufacturing complexity drivers can be distinguished between internal and external factors and so-called complexity drivers [10]. To gain an understanding of the complexity, these external and internal drivers need to be identified first and their dependency on products and processes needs to be described subsequently [11]. Aelker et al., [12] stated that the most accepted differentiation is between the complexity arising from within a company (internal complexity), and the complexity caused by factors external to the organisation (external complexity). Yet, reviewing of the manufacturing complexity drivers, which provides the necessary knowledge to complete the first step of a complexity management initiative. Understanding and analysing the complexity drivers first will be an effective way to proceed to develop a clear strategy to deal with complexity [13].

Therefore, this initial study was conducted to explore the effect of complexity drivers in manufacturing productivity performance, based on two components namely Current Manufacturing Performance (CMP) and Manufacturing Complexity Driver (MCD) with the priority and the current achievement's practice in Malaysia's manufacturing industry. The findings can be used in shaping a more inclusive action to attain higher productivity performance. In addition, the results from this study can be used by the manufacturer, particularly to identify the main of MCD in order to achieve high CMP in production operations. Moreover, academicians can also use the evidence from this study to develop a new manufacturing framework to strengthen the current practice in manufacturing operations with the existing complexity drivers. The following sections would explain the research method underpinning the survey information, the results of statistical analysis from the survey, the measures of MCD and CMP, the relation between MCD and CMP and conclusions.

\section{RESEARCH METHOD}

The survey questionnaire is one data collection methods to obtain quantitative data for statistical testing of the hypothesis from the literature reviews [14-15]. The analysis was based on data obtained from the quantitative method by using statistical package SPSS. A questionnaire comprised of 28 items on CMP and 15 items MCD. For each item, the respondents were asked to rate each item with priority and achievement based on a five points Likert's scale (e.g.: 1=unimportant to $5=$ critical for priority level and $1=$ very poor to $5=$ very good for current achievement). MCD is the dependent variable in the preliminary study to determine the significant driver through the mean score. CMP acts as the dependent variable to define the critical gap between the priority and the current achievement of each item in order to achieve better productivity. The internal consistency and reliability of the survey were tested using the Cronbach's $\alpha$ reliability test [16]. Abolhassani et al., [17] stated that Spearman's correlation evaluates a relationship between two variables, without making any assumptions about the frequency distribution of the variables and it was applied to measure the correlation of the relation of CMP and MCD. Out of 150 questionnaires sent, a total 61 were completed and returned. After a screening process, 54 of those completed with useful information went on for further analysis. With a response rate of 40.7 percent, it was believed that the answers would be reasonable and sampling technique is not used because of the survey not representing any population. The other intention is that this study is only an initial study in manufacturing complexity drivers on performance in Malaysia's industry.

\section{RESULT AND DISCUSSION}

Descriptive statistics such as frequency, percentage and mean are the main statistical analysis. The survey questionnaire has been addressed to the appropriate person who with at least two years' experience in the company. The job title of the respondents is categorised into three types which are chief executive officer (CEO)/ director, manager/executive, engineer and others. Most of the respondents are engineer position which had $50.9 \%$. Besides, the highest number of company ownership was from foreign countries (74.5\%) typically are Asian company, followed by a local company (25.5\%). $72.8 \%$ of the company has more than $50 \%$ of the main business operation is manufacturing operation. $72.5 \%$ of the company has more than $50 \%$ of original equipment manufacturer (OEM) product.

Most of the respondents were from the electric/electrical products group $(36.4 \%)$, other products group and automotive products group (16.4\%), other product group (14.5\%), chemical/scientific products group (12.7\%), $10.9 \%$ of the company have various product groups such as automotive, electric/electrical and 
mechanical and lastly, from mechanical engineering products group $(9.1 \%)$. The majority of the respondents were foreign companies with more than 500 employees (74.5\%), while the lowest respondent was from the local companies that 50 to 100 employees $(5.5 \%)$. Meanwhile, $87.3 \%$ of the respondents were experienced with ISO 9001. Furthermore, the other management certification obtained by the company such as TS 16949 (30.9\%), ISO14001 (67.3\%), OHSAS $18001(52.7 \%)$ while 12.7 percent possess the other management certification such as ISO 13485 and ISO 9002.

\section{ANALYSIS OF MANUFACTURING COMPLEXITY DRIVER (MCD)}

In terms of MCD, the Cronbach's alpha analysis shows that all regularly reliable at a value of 0.874 for priority level and 0.871 for the current achievement. The dispersal of mean score for priority and current achievement of MCD are illustrated in Figure 1. The respondents agreed that all 15 items have fulfilled the priority where most of the manufacturer are prioritised increases of customer demands (MCD13) has the highest mean score of 4.27. This followed by the machine efficiency (MCD7), machine utilisation (MCD1), and capacity planning (MCD2) at a mean score of 4.18, 4.16 and 4.13 respectively. However, process selection (MCD4) is still less popular as this item ranked the lowest score with a mean score of 3.40. Increases of customer demands (MCD13) has the highest mean score too for MCD current achievement value at 3.85 , followed by machine utilisation (MCD1) and finish product management (MCD12) at a mean score value of 3.82 and 3.80 respectively. Respondents also agreed that capacity planning (MCD2) and this reported a mean score value of 3.72. In contrast, process selection (MCD4) has less influence on the respondents appraised this with the lowest mean score value of 3.26. Based on Figure 1, increases of customer demands (MCD13) is the main MCD item that prioritised and achieved by most of the company because with customer demands the company have to grow their products unceasingly and adapt their production program and quantity [18].

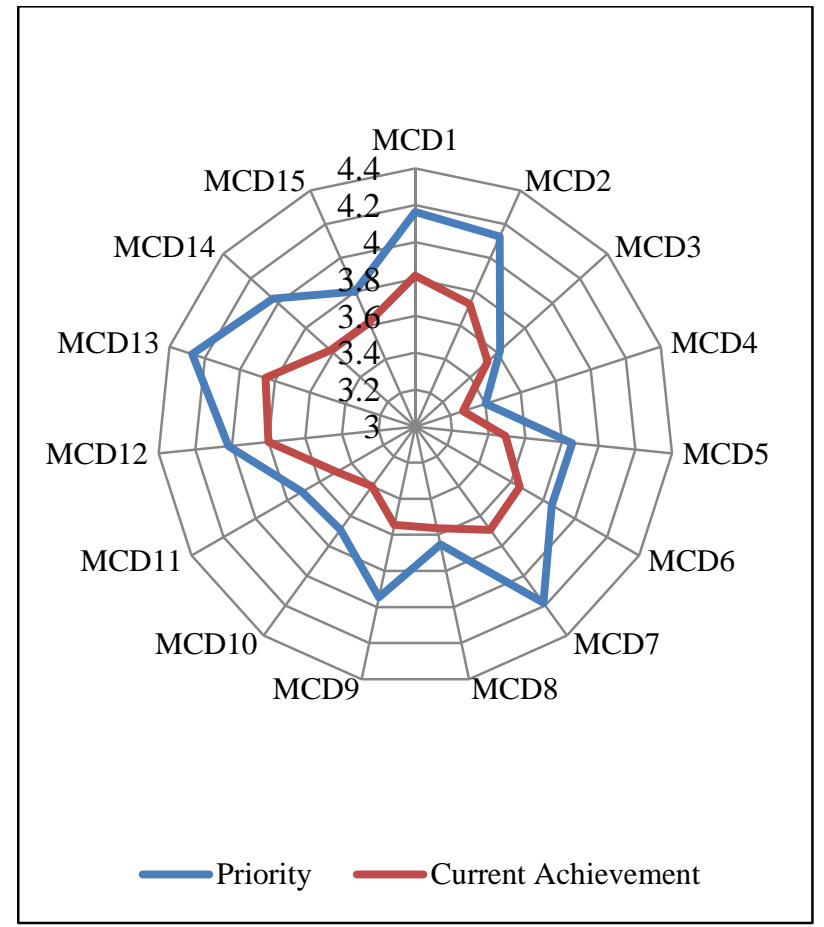

Figure 1: The performance of MCD in priority level and current achievement

\section{MEASURES OF CURRENT MANUFACTURING PERFORMANCE (CMP)}

The Cronbach's alpha analysis shows that all CMP items in the questionnaires were consistently reliable at a value of 0.907 for priority level and 0.931 for the current achievement of CMP. The respondents agreed that all 28 items have fulfilled the priority where most of the manufacturer are prioritised product quality (CMP27) has the highest mean score of 4.64 which illustrated in Figure 2. This followed by the on-time delivery (CMP7), minimum cost (CMP26), and efficient space utilisation (CMP24) at a mean score of 4.54, 4.22 and 4.02 respectively. However, zero WIP (one-piece flow) (CMP21) is still less popular as this item ranked the lowest score with a mean score of 3.12. As for CMP current achievement, on-time delivery (CMP7) has the highest mean score value at 4.10 , followed by product quality (CMP27) and minimum cost (CMP26) at a mean score value of 3.96 and 3.78 respectively. Respondents also agreed that adaptation of new technology (CMP1) and this reported a mean score value of 3.68. In contrast, zero WIP (one-piece flow) (CMP21) has less influence as the respondents appraised this with the lowest mean score value of 2.98 . 


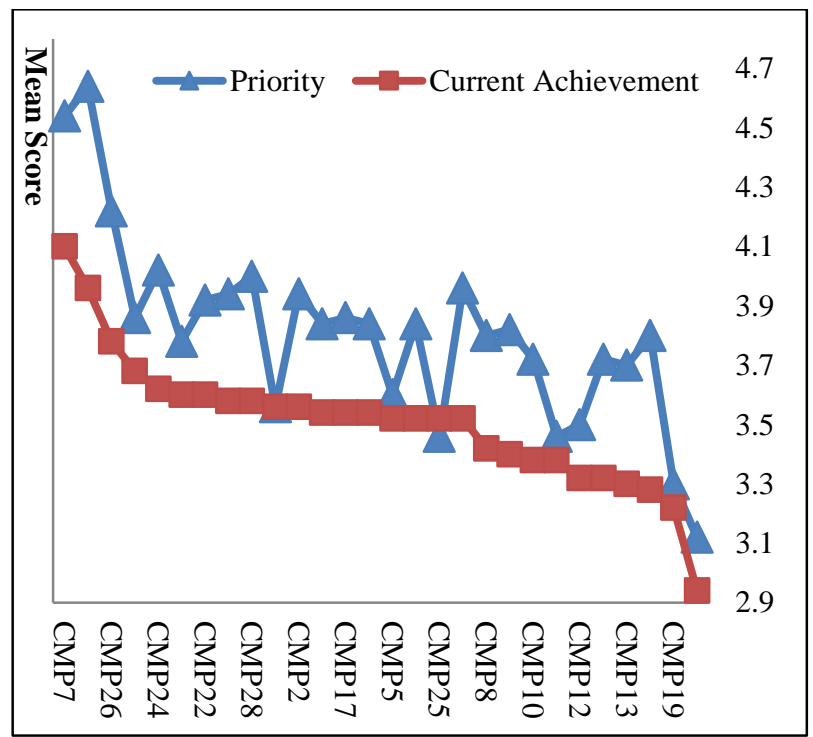

Figure 2: Comparison of mean score differences between priorities and the current achievement of manufacturing performance at manufacturing industry in Malaysia

As shown in Figure 3, the largest gap that formed between priority and current achievement is CMP 27 followed by CMP20 and CMP 26 which indicated that the current achievement of CMP is lower than the priority status. This result shows that most of Malaysia's manufacturing industry has a high focus on product quality, on-time delivery and minimum cost to achieve better manufacturing performance. This is not surprising because the focus on dealing with product quality and on-time delivery issues are crucial to remaining competitive in a modern manufacturing era in order to minimise cost. This is evidently shown in Figure 2 where these three components (product quality, on-time delivery and minimum cost) have the higher mean score compared to the others component measured. Manufacturing industries in pursuit of cost and time reduction without decreasing product quality $[17,19-$ 20]. Improved product quality and on-time delivery result in improved performance [21]. Antony et al., [22] implemented Six Sigma to ensure there was an improvement in the on-time delivery which was able to cost reduction. Most of the manufacturing industries aim the key performance measures are to increase yield, to maintain the quality of products, and to reduce the cost of operations [23].

Efthymiou et al., [24] stated that demand fluctuation along with the requirements of high product quality, low-cost, short lead time and high customisation may lead to an increase in manufacturing complexity in the globalised and interconnected market. This fact indicates that Malaysia's manufacturing industry nowadays possess to attain good manufacturing performance particularly to remain competitive in a new manufacturing environment and the complexity arises in the manufacturing.

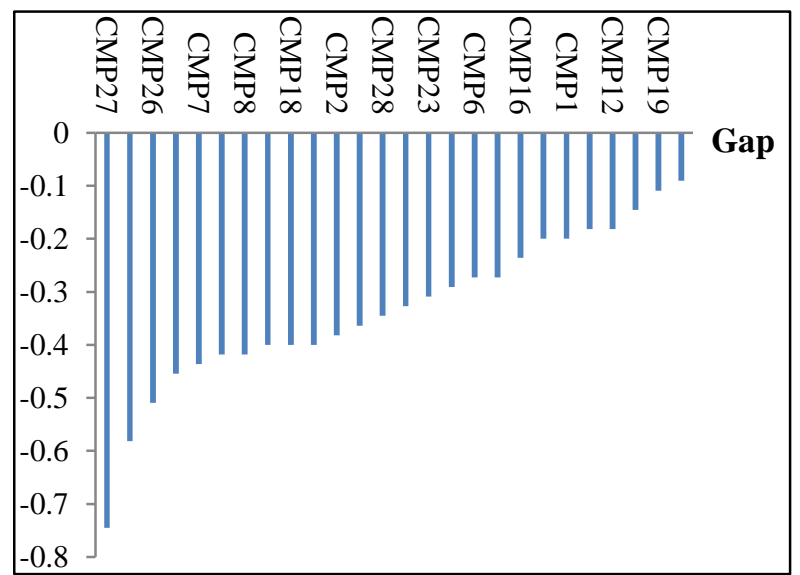

Figure 3: The difference gap between priority level and current achievement status for CMP

\section{THE RELATION BETWEEN MANUFACTURING COMPLEXITY DRIVER AND CURRENT MANUFACTURING PERFORMANCE}

In this study, from a total of 420 matrices of the relationship created from Spearman's correlation analysis between CMP with the MCD. The proposed hypothesis is addressed in this section which is:

$\mathrm{H}_{0 \mathrm{~A}}$ : All MCD is not significant correlation with CMP in priority level.

$\mathrm{H}_{1 \mathrm{~A}}$ : All MCD is a significant correlation with CMP in priority level.

$\mathrm{H}_{0 \mathrm{~B}}$ : All MCD is not significant correlation with CMP in current achievement.

$\mathrm{H}_{1 \mathrm{~B}}$ : All MCD is a significant correlation with CMP in current achievement.

Table 1 shows the test results between priority level and current achievement related to CMP and MCD. The Spearman $\rho$ correlation coefficient ranged from 0.021 to 0.716 for priority status and ranged from 0.031 to 0.699 for current achievement, at a significant level of 0.01 , which indicated a moderate to the high-linear association between these variables. The analysis also shows that the item in the CMP has a significant relationship with $\mathrm{MCD}$, where a strong correlation relationship existed between the efficient production levelling (finished goods) (CMP17) with finished product management (MCD12) at a value of 0.741 for priority status, the null hypothesis, $\mathrm{H}_{0 \mathrm{~A}}$ is rejected for these items. Production levelling is the lean concept for production smoothing [25] concluded that with production levelling able to manage product flow operation efficiently.

The correlation analysis between CMP and MCD for current achievement showed a significant value, 0.689 
within minimising the number of the workstation (CMP25) and factory transportation system (MCD8). The null hypothesis, $\mathrm{H}_{0 \mathrm{~B}}$ is rejected for these items since the items are significant correlate with MCD and CMP. Pourvaziri and Pierreval [26] identified that the location of machines is one of the key issues regarding manufacturing systems' performance. Indeed, if the material flow between two machines becomes too high, then it may be necessary to add new transporters to the system, which adds new costs. machines or workstations with high flow rates are allocated close to each other to minimize the total distance of the material flow.

Table 1: Spearman correlation between MCD against Current Manufacturing Performance

\begin{tabular}{lll}
\hline \multirow{2}{*}{ Item } & \multicolumn{2}{c}{ Current Manufacturing Performance } \\
\cline { 2 - 3 } & Priority & Current Achievement \\
\hline MCD2 & CMP20 & CMP7,CMP11 \\
MCD5 & - & CMP23 \\
MCD6 & CMP24 & CMP12, CMP25 \\
MCD7 & CMP28 & CMP18, CMP22 \\
MCD8 & - & CMP24,CMP25 \\
MCD9 & CMP17 & - \\
MCD10 & CMP19 & CMP7,CMP18 \\
MCD11 & CMP14 & - \\
MCD12 & CMP14, CMP17 & - \\
\hline
\end{tabular}

\section{CONCLUSION}

As a conclusion, this initial study has shown that the MCD has a strong influence on the manufacturing performance. Coupled with correlation analysis, this showed that each of the practices in MCD has a significant positive correlation with each item in the manufacturing sustainability components. The study was still relatively exploratory. Future studies could investigate the management of complexity with the existed complexity drivers at Malaysia's manufacturing industry. The findings in this study can be used as a basis for the next stage of a study in developing a more widespread approach to manufacturing complexity management, primarily in Malaysia's manufacturing industry.

\section{ACKNOWLEDGMENTS}

This research was co-funded under Ministry of Higher Education (MOHE), FRGS Grant (FRGS/1/2016/TK03/FTK-AMC/F00324) and Zamalah Scholarship provided by Universiti Teknikal Malaysia Melaka (UTeM).

\section{REFERENCES}

[1] Reuter, C., Prote, J.-P., \& Stöwer, M. (2016). Evaluation of performance differences between manufacturing sites. Procedia CIRP, 50, 342-347.
[2] Wan Hasrulnizzam, W. M. (2008). Industrial Types of Manufacturing Complexity. In Proceedings of the National Seminar on Engineering \& Technopreneurship (pp. 209-213).

[3] Manyika, J., Sinclair, J., Dobbs, R., Strube, G., Rassey, L., Mischke, J., ... Ramaswamy, S. (2012). Manufacturing the Future: The Next Era of Global Growth and Innovation. McKinsey Global Institute, (November), 184.

[4] Eleventh Malaysia Plan. (2015). Percetakan Nasional Malaysia Berhad, 17.

[5] S.Mattsson, P.Gullander, \& A.Davidsson. (2011). Method for Measuring Production Complexity. In International Manufacturing Conference IMC 28Manufacturing Sustainability.

[6] Popovics, G., \& Monostori, L. (2016). An approach to Determine Simulation Model Complexity. Procedia \{CIRP\}, 52, 257-261.

[7] Alkan, B., Vera, D., Ahmad, M., Ahmad, B., \& Harrison, R. (2016). Design Evaluation of Automated Manufacturing Processes Based on Complexity of Control Logic. 26th CIRP Design Conference, 50, 141146.

[8] Elmaraghy, W. H., Elmaraghy, H. A., Tomiyama, T., \& Monostori, L. (2012). Complexity in Engineering Design and Manufacturing. CIRP Annals Manufacturing Technology, 61(January), 793-814.

[9] Gerschberger, M., Engelhardt-Nowitzki, C., Kummer, S., \& Staberhofer, F. (2012). A model to determine complexity in supply networks. Journal of Manufacturing Technology Management, 23(8), 10151037.

[10] Vogel, W., \& Lasch, R. (2016). Complexity Drivers in Manufacturing Companies: a Literature Review. Logistics Research, 9(1), 25.

[11] Kohr, D., Budde, L., \& Friedli, T. (2017). Identifying Complexity Drivers in Discrete Manufacturing and Process Industry. Procedia CIRP,0,1-6.

[12] Aelker, J., Bauernhansl, T., \& Ehm, H. (2013). Managing Complexity in Supply Chains: A Discussion of Current Approaches on The Example of The Semiconductor Industry. Procedia CIRP, 7(14), 79-84.

[13] Serdarasan, S. (2013). A Review of Supply Chain Complexity Drivers. Computers and Industrial Engineering, 66(3), 533-540.

[14] Özşahin, M., Sezen, B., \& Çankaya, S. Y. (2013). Effects of Green Manufacturing and Eco-innovation on Sustainability Performance. Procedia - Social and Behavioral Sciences, 99, 154-163.

[15] Zhang, L., \& Chen, X. (2016). Role of Lean Tools in Supporting Knowledge Creation and Performance in Lean Construction. Procedia Engineering, 145, 12671274.

[16] Jasti, N. V. K., \& Kodali, R. (2014). Validity and reliability of lean manufacturing frameworks. International Journal of Lean Six Sigma (Vol. 5).

[17] Abolhassani, A., Ky, L., \& Gopalakrishnan, B. (2016). Lean and US manufacturing industry: popularity of practices and implementation barriers. International 
Journal of Productivity and Performance Management, 65(7), 875-897.

[18] Cichos, D., \& Aurich, J. C. (2016). Support of Engineering Changes in Manufacturing Systems by Production Planning and Control Methods. Procedia CIRP, 41, 165-170.

[19] Efthymiou, K., Pagoropoulos, A., Papakostas, N., Mourtzis, D., \& Chryssolouris, G. (2012). Manufacturing Systems Complexity Review: Challenges and Outlook. In Procedia CIRP (Vol. 3, pp.644-649).

[20] Ringena, G., Aschehouga, S., Holtskogb, H., \& Ingvaldsena, J. (2014). Integrating Quality and Lean into a Holistic Production System. Procedia CIRP, 17, 242-247.

[21] Psomas, E., \& Kafetzopoulos, D. (2014). Performance measures of ISO 9001 certified and non-certified manufacturing companies. Benchmarking, 21(5), 756.

[22] Antony, J., Gijo, E. V, Kumar, V., \& Ghadge, A. (2016). A multiple case study analysis of Six Sigma practices in Indian manufacturing companies.

\begin{tabular}{ll} 
APPENDIX \\
1.Information on Current Manufacturing \\
Performance (CMP) \\
What are your current manufacturing performances in \\
your company from the past two (2) years? (On a five \\
point Likert-scale) \\
\hline Item & \multicolumn{1}{c}{ Manufacturing Performance } \\
\hline CMP1 & Adaptation of new technology \\
CMP2 & Decrease customer lead time \\
CMP3 & Decrease throughput time \\
CMP4 & Enhanced product variety \\
CMP5 & High capacity of Innovation \\
CMP6 & Minimise setup time \\
CMP7 & Ontime delivery \\
CMP8 & Speed up changeover time \\
CMP9 & Effective machine optimisation \\
CMP10 & Increasing Kaizen activities \\
CMP11 & Minimise machine configuration \\
CMP12 & Operator flexibility and innovativeness \\
CMP13 & Optimise Poka-Yoke \\
CMP14 & Proactive Total Preventive Maintenance \\
CMP15 & Process line balancing \\
CMP16 & Effective pace of production (Takt time) \\
CMP17 & Efficient production levelling (finished \\
& goods) \\
CMP18 & Organised Just-in-Time (JIT) for raw \\
CMP19 & Organised Kanban system for Work-in- \\
CMP20 & Zrogress (WIP) missing/misplace material \\
CMP21 & Zero WIP (one piece flow) \\
CMP22 & Effective layout configuration \\
CMP23 & Effective material flow \\
CMP24 & Efficient space utilisation \\
CMP25 & Minimise number of workstation \\
CMP26 & Minimum cost \\
CMP27 & Product quality \\
CMP28 & Simplified operation procedure \\
\hline &
\end{tabular}

International Journal of Quality \& Reliability Management International Journal of Quality \&amp; Reliability Management International Journal of Quality \&amp; Reliability Management Iss International Journal of Quality \& Reliability Management, 338(8), 1138-1149.

[23] Chongwatpol, J. (2015). Prognostic analysis of defects in manufacturing. Industrial Management and Data Systems, 115(1), 64-87.

[24] Efthymiou, K., Pagoropoulos, A., Papakostas, N., Mourtzis, D., \& Chryssolouris, G. (2012). Manufacturing Systems Complexity Review: Challenges and Outlook. In Procedia CIRP (Vol. 3, pp. 644-649).

[25] Clotet, J. F. (2015). Lean Production Planning and Control in Semi-Process Industry. Norwegian University of Science and Technology.

[26] Pourvaziri, H., \& Pierreval, H. (2017). Dynamic facility layout problem based on open queuing network theory. European Journal of Operational Research, 259(2), 538-553.

\begin{tabular}{ll} 
2. Information on Manufacturing Complexity (MC) \\
What are your complexity drivers in your company \\
from the past two (2) years? (On a five point Likert- \\
scale from unimportant to critical for priority and very \\
poor to very good for current achievement) \\
Item & \multicolumn{1}{c}{ Manufacturing Complexity Drivers } \\
\hline MCD1 & Machine utilisation \\
MCD2 & Capacity planning \\
MCD3 & High product mix \\
MCD4 & Process Selection \\
MCD5 & Material handling management \\
MCD6 & Space utilisation \\
MCD7 & Machine efficiency \\
MCD8 & Factory transportation system \\
MCD9 & Inventory forecast \\
MCD10 & WIP product handling \\
MCD11 & Raw material handling \\
MCD12 & Finish product management \\
MCD13 & Increases of customer demands \\
MCD14 & Increases of customer numbers \\
MCD15 & Specifications of products
\end{tabular}

